\title{
Isolation and Identification of Phenylethanoid Glycosides from Aloysia polystachya and Its Activity as Inhibitors of Monoamine Oxidase-A
}

\section{(웅 $\odot \Theta$}

\author{
Authors \\ Ana Maria S. Pereira1, Camila C. Guimarães ${ }^{1}$, Sarazete I. V. Pereira ${ }^{1}$, Eduardo J. Crevelin², Gustavo H. T. Pinto¹, \\ Lucas J. F. Morel ${ }^{1}$, Bianca W. Bertoni ${ }^{1}$, Suzelei C. França ${ }^{1}$, Silvia H. Taleb-Contini ${ }^{1}$
}

\section{Affiliations}

1 Departamento de Biotecnologia em Plantas Medicinais, Universidade de Ribeirão Preto (UNAERP), Ribeirão Preto, SP, Brazil

2 Departamento de Química, Faculdade de Filosofia, Ciências e Letras de Ribeirão Preto, Universidade de São Paulo (USP), Monte Alegre, Ribeirão Preto, SP, Brazil

\section{Key words}

aloysia polystachya, verbenaceae, antidepressant activity, phenylethanoids, monoamine oxidase inhibitors

$\begin{array}{ll}\text { received } & 04.06 .2018 \\ \text { revised } & 19.10 .2018 \\ \text { accepted } & 24.10 .2018\end{array}$

Bibliography

DOI https://doi.org/10.1055/a-0787-1665

Planta Med Int Open 2019; 6: e1-e6

(c) Georg Thieme Verlag KG Stuttgart · New York

ISSN 2509-9264

\section{Correspondence}

Ana Maria S. Pereira

Departamento de Biotecnologia em Plantas Medicinais

Universidade de Ribeirão Preto

Av. Costábile Romano 2201

14096-900 Ribeirânia

Ribeirão Preto, SP

Brazil

Tel.: + 55/360/36 727

apereira@unaerp.br 丹upporting Information for this article is available online at http://www.thieme-connect.de/products

\begin{abstract}
Aloysia polystachya is used as a sedative and antidepressant by the indigenous populations of Argentina and Paraguay, but the compounds associated with these activities have not been determined. We have separated and identified the main constituents of the hydroethanolic extract of $A$. polystachya by ultraperformance liquid chromatography-mass spectrometry and confirmed the presence of acteoside, isoacteoside, 6'-acetylacteoside, and 4',4"',5,5"'-tetrahydroxy-6,6",3"'-trimethoxy-[C7O-C7']-biflavone by NMR spectroscopy. Inhibitory activities of the hydroethanolic extract and purified phenylethanoid glycosides against monoamine oxidase-A were assessed using a standard fluorometric assay. The hydroethanolic extract inhibited monoamine oxidase-A activity in a dose-dependent manner with an $\mathrm{IC}_{50}$ of $9.2 \mu \mathrm{g} / \mathrm{mL}$, while the selective monoamine oxidase inhibitor clorgyline exhibited an $\mathrm{IC}_{50}$ of $0.06 \mu \mathrm{g} / \mathrm{mL}(0.22 \mu \mathrm{M})$. Acteoside was the strongest inhibitor of monoamine oxidase-A $\left(\mathrm{IC}_{50}\right.$ value of $\left.5 \mu \mathrm{M}\right)$, whereas isoacteoside and 6'-acetylacteoside showed $\mathrm{IC}_{50}$ values of around $10 \mu \mathrm{M}$. The results showed that phenylethanoids from a hydroethanolic extract of $A$. polystachya have been found to have inhibitory activity against monoamine oxidase-A. It is likely that the mode of action of the acteosides is multi-targeted, involving the downregulation of inflammatory molecules and neutralization of oxidation reactions as well as inhibition of monoamine oxidase-A.
\end{abstract}

\section{Introduction}

According to a recent report from the World Health Organization [1], more than 320 million people (4.4\% of the world population) suffer from depression and anxiety disorders, with around 800 thousands suicides per year being committed as a result of these mental issues. Although treatment with synthetic antidepressants is available, many patients suffer from side effects such as dry mouth, constipation, dizziness, blurred vision, increased appetite, weight gain, insomnia, and kidney problems [2]. For this reason, approaches using complementary and alternative medicine, including phytotherapy, have been used in the treatment of several types of mental disorders [3]. 
Various preclinical and clinical studies have provided evidence in support of the benefits of plant-based medicines in the treatment of general and specific anxiety disorders [4, 5]. Of particular interest are investigations into the anxiolytic properties of Aloysia polystachya (Griseb.) Moldenke (Verbenaceae), an aromatic species found mainly in Argentina and Paraguay. According to ethnopharmacological studies, local populations use the plant, which is commonly known as burrito, as a digestive, sedative, and antidepressant tonic $[6,7]$. Although the anxiolytic and antidepressant properties of hydroethanolic extracts from $A$. polystachya have been confirmed by preclinical studies [8-10], no phytochemical investigations have been performed with the aim of identifying the compounds associated with these activities.

It has previously been shown that the antidepressant activities of some medicinal plants, for example, Hypericum perforatum L. (Hypericaceae) and Peganum harmala L. (Nitrariaceae), are associated with the inhibition of monoamine oxidase-A (MAO-A) [11-13]. The MAO family is distributed throughout the central and peripheral nervous systems and overexpression of these enzymes promotes the oxidative deamination of monoamines with reductions in the levels of the neurotransmitters serotonin, norepinephrine, and dopamine, which result in the onset of psychiatric disorders. Such deamination processes also generate substances such as hydrogen peroxide, oxygen free radicals, and aldehydes that are responsible for the oxidative stress of cells. MAOs exist in two major isoforms that differ with respect to distribution, substrate specificity, and sensitivity to inhibitors. The MAO-A isoform plays an important role in depression and anxiety disorders, while MAO-B is involved in neurodegenerative diseases [13-17].

In light of the above, we hypothesized that the anxiolytic and antidepressant properties of $A$. polystachya derive, at least in part, from the presence of inhibitors of MAO-A. In order to test this hypothesis, we identified the active principles present in the hydroethanolic extract from leaves of $A$. polystachya and assessed the effects of the crude extract and the main constituents isolated therefrom on MAO-A activity.

\section{Results and Discussion}

The hydroethanolic extract from leaves of $A$. polystachya was submitted to ultra-performance liquid chromatography-mass spectrometry (UPLC-MS), and the chromatogram so obtained is presented in $>$ Fig. 1a. The main components of the extract were purified by column chromatography and reversed-phase high-performance liquid chromatography (RP-HPLC), and identified as acteoside (syn verbascoside), isoacteoside, 6 '-acetylacteoside, and 4',4"',5,5"'-tetrahydroxy-6,6",3"'-trimethoxy-[C7-O-C7'”]-biflavone by comparison of their ${ }^{1} \mathrm{H}$ - and ${ }^{13} \mathrm{C}-\mathrm{NMR}, \mathrm{HSQC}, \mathrm{HMBC}$ ( Table 1S, 2S, Supporting Information), and MS data ( $\triangleright$ Fig. 1b-e) with values reported in the literature [18-20]. The concentration of acteoside in the hydroethanolic extract, as determined by HPLC, was $108.65 \pm 1.3 \mu \mathrm{g} / \mathrm{mg}$ of dried extract. This represents the first record of the constituents of extracts of leaves from $A$. polystachya, although the essential oil of the plant has been analyzed previously and found to contain the monoterpenes carvone and limonene as the major components [21].
The crude hydroethanolic extract from leaves of $A$. polystachya inhibited MAO-A activity in a dose-dependent manner ( $\mathbf{F i g . ~ 2 a ) ~}$ with an $\mathrm{IC}_{50}$ of $9.2 \mu \mathrm{g} / \mathrm{mL}$, while the selective MAO inhibitor clorgyline exhibited an $\mathrm{IC}_{50}$ of $0.06 \mu \mathrm{g} / \mathrm{mL}(0.22 \mu \mathrm{M})$. The purified acteosides also exhibited inhibitory activities against MAO-A ( $\vee$ Fig. $\mathbf{2 b}$ ), with acteoside presenting the lowest $I C_{50}$ value of $5 \mu \mathrm{M}(3.1 \mu \mathrm{g} / \mathrm{mL})$ followed by isoacteoside with an $\mathrm{IC}_{50}$ of $10.1 \mu \mathrm{M}(6.3 \mu \mathrm{g} / \mathrm{mL})$ and 6'-acetylacteoside with an $\mathrm{IC}_{50}$ of $9.5 \mu \mathrm{M}(6.3 \mu \mathrm{g} / \mathrm{mL})$. Inhibition of MAO-A leads to the reestablishment of the levels of serotonin, norepinephrine, dopamine, and tyramine, which are key neurotransmitters in the control of anxiety and depression [16]. Thus, the presence of diverse MAO-A inhibitors in leaves of $A$. polystachya explains, at least in part, the previously reported antidepressant and anxiolytic activity of the species [8-10].

The use of multicomponent plant mixtures can be advantageous in the treatment of diseases of complex etiology such as anxiety, depression, and other neurological conditions. Currently, the use of phytomedicines in the treatment of diseases that affect the nervous system is based on the paradigm of multi-target-directed ligands, i.e., pharmaceuticals that have multi-target activities resulting from the presence of substances such as polyphenolics with anti-inflammatory, antioxidant, and MAO inhibitory properties that are capable of conferring neuroprotection [20, 22-25].

It is worth noting, however, that the polar character of polyphenolic substances could hinder interactions with their molecular targets. Nevertheless, clinical studies have demonstrated that the contact between polyphenolics and nonpolar secondary metabolites present in the extracts may modify the permeability of cell membranes and facilitate the uptake of polar compounds [23]. Thus, complex plant extracts containing multi-target agents that interact with their receptors in a pleiotropic fashion generate a pharmacological synergism that affects numerous processes, including the movement of polar metabolites across cell membranes. In this context, Li et al. [26] employed a zebrafish model to demonstrate that acteoside could penetrate the blood-brain barrier, and proposed that the phenylethanoid glycoside may have a potential therapeutic effect in Parkinson's disease.

Monoaminergic neurotransmitters are the main targets of modern antidepressants since their deficiencies are responsible for the debilitating symptoms of depression. A recent in vivo study demonstrated that the ethanolic and aqueous extracts of Lippia citriodora (Verbenaceae) and their main component acteoside exhibited anxiolytic, hypnotic, and muscle relaxant effects, and these properties were attributed, in part, to an interaction with the type A gammaaminobutyric acid $\left(G A B A_{A}\right)$ receptor [27].

Clinical studies have revealed that drugs with the capacity to block inflammatory cytokines, such as TNF- $\alpha$, or other components of the inflammatory signaling pathway, for example, cyclooxygenase-2 (COX-2), are effective in reducing depressive symptoms in patients with rheumatoid arthritis, psoriasis, and cancer, as well as those suffering from major psychiatric disorders [28]. In this context, it has been reported that acteoside can attenuate the production and release of inflammatory molecules, such as nitric oxide (NO), TNF- $\alpha$, and interleukin 12 (IL-12) in lipopolysaccharide/interferon-gamma (LPS/IFN- $\gamma$ )-stimulated macrophages [29], as well as histamine and arachidonic acid in RBL-2H3 mast cells [30]. In addition, acteoside is able to reduce the levels of TNF- $\alpha, I L-1 \beta, I L-8$, IL-6, and NO, and to activate caspase- 1 , nuclear factor-kappa-B 


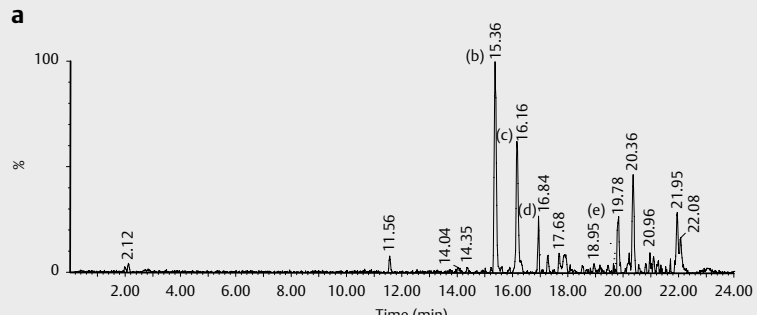

b
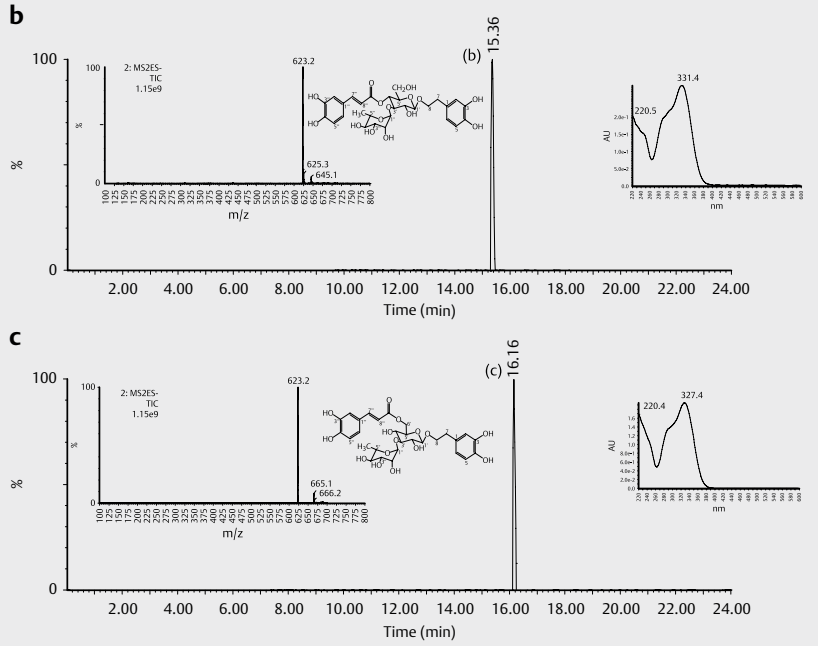

d

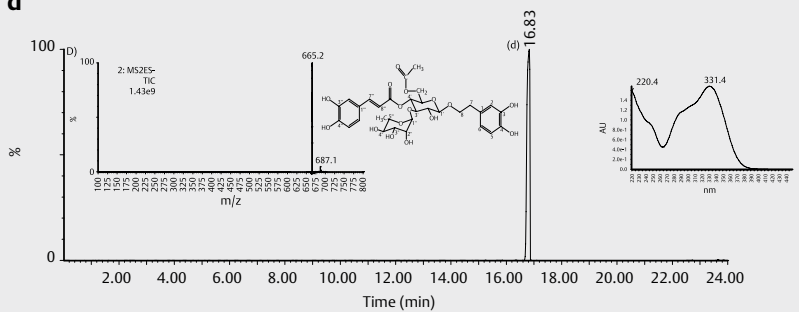

e

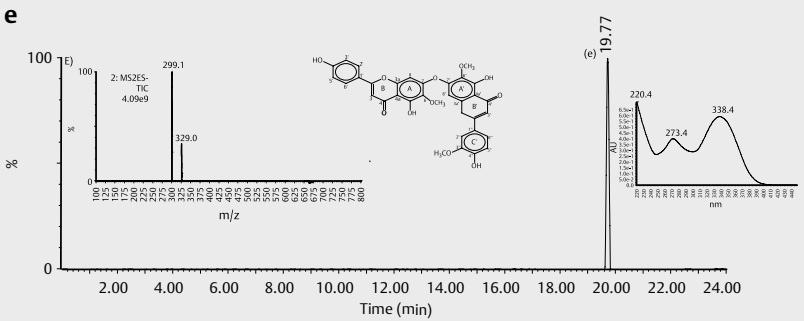

- Fig. 1 UPLC-MS chromatograms of the hydroethanolic extract from A. polystachya $\mathbf{a}$ and standard compounds acteoside $\mathbf{b}$, isoacteoside $\mathbf{c}$, 6'-acetylacteoside d, and 4',4"',5,5"'-tetrahydroxy-6,6", 3'"'-trimethoxy-[C7-O-C7"']-biflavone e with inserts showing the respective UV and negative ion electrospray ionization mass spectra (ESI/MS).

(NF-kB), NO synthase, and activator protein-1 [31] induced by IL-32 and/or LPS in TH-1 cells and macrophages [32].

Some of these inflammatory mediators, such as IFNs, IL-6, IL-8, and $\mathrm{IL}-1 \beta$, have been found at abnormal levels in both peripheral and postmortem tissue samples from depressed individuals, and have been related to the symptoms of depression [33]. Activation of these molecules by psychosocial stressors may promote significant functional changes in the brain, leading to the development of depressive behavior and other psychiatric disorders. IFNs, IL-1 $\beta$, and TNF- $\alpha$, for example, may increase the expression and function of serotonin, noradrenaline, and dopamine receptor pumps, thus reducing the availability of these neurotransmitters in the synaptic cleft [28]. In addition, IFN- $\gamma$, IL-6, TNF- $\alpha$, and oxidative stress can activate indoleamine 2,3 dioxygenase (IDO), an enzyme responsible for the degradation of tryptophan and, thereby, reduce the concentration of the primary precursor of serotonin synthesis [34].

Acteoside, isoacteoside, and 6'-acetylacteoside contain hydroxyphenylethyl and caffeoyl moieties that are known to be associated with antioxidant properties [35, 36], and acteoside itself exhibits considerable antioxidant activity [37]. Studies have shown that acteoside inhibits the aggregation of $\beta$-amyloid peptide $(A \beta)$ in a dosedependent manner, functions as a neuroprotective agent, and enhances memory, and these properties have been attributed to the antioxidant activity of the agent $[38,39]$. Considering that numerous phenolic-rich species with antioxidant properties are used in the treatment of neurological disorders [15], it has been suggested that the antidepressant and anxiolytic effects of the phenylethanoid gly- cosides isolated from A. polystachya may also result from their antioxidant activities. This supposition was supported by Xu et al. [40], who presented evidence concerning the relationship between increased oxidative stress and depression/anxiety.

Based on the above, we conclude that the antidepressant properties of the hydroethanolic extract from leaves of $A$. polystachya, and of the purified phenylethanoids isolated therefrom, can be explained by multi-target modes of action involving the inhibition of MAO-A, downregulation of inflammatory molecules, and neutralization of oxidation reactions. Hence, the results presented herein support our original hypothesis that the anxiolytic and antidepressant activities of the hydroethanolic extract of $A$. polystachya result, at least in part, from the inhibition of MAO-A. However, the structure-activity relationship of the phenylethanoid glycosides identified in this study requires further attention so that novel molecules can be designed for the treatment of specific neurological disorders.

\section{Materials and Methods}

\section{Plant material}

Leaves of A. polystachya were harvested at the Farmácia da Natureza da Terra de Ismael (Jardinópolis, SP, Brazil) in January 2016. Plant material was identified by Dr. Lúcia Rossi (Instituto Botânico, São Paulo, SP, Brazil), and a voucher specimen was deposited in the Herbarium of Medicinal Plants at UNAERP with voucher number 
a

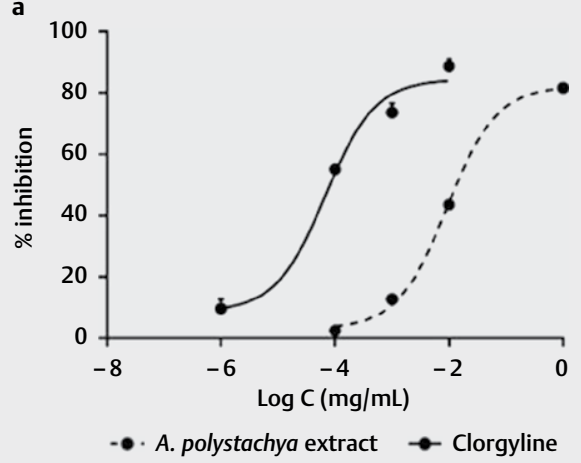

b

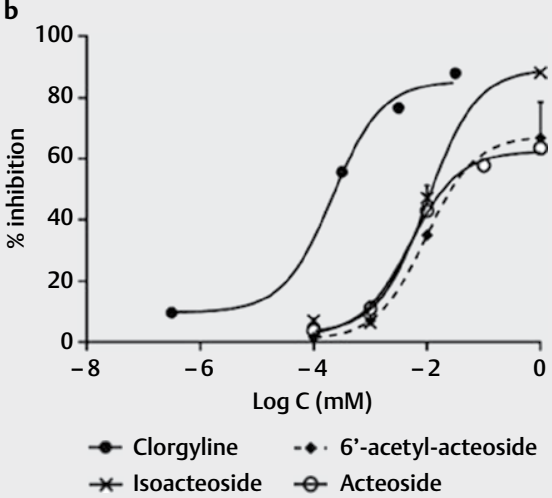

- Fig. 2 Inhibition of monoamine oxidase-A by a the crude hydroethanolic extract from leaves of $A$. polystachya and $\mathbf{b}$ the main constituents of the hydroethanolic extract, namely, acteoside, isoacteoside, and 6'-acetylacteoside. For comparison, the inhibitory activity of the positive control clorgyline is shown in both panels.

HPM-1213. Permission to evaluate the bioactivities of the extracts from Brazilian plants was granted by the Instituto Brasileiro do Meio Ambiente e dos Recursos Naturais Renováveis (no. 02001.005074/ 2011-19).

\section{Preparation of the hydroethanolic extract of Aloysia polystachya}

Leaves $(1000 \mathrm{~g})$ were dried for $72 \mathrm{~h}$ in a circulating air oven at $45^{\circ} \mathrm{C}$, pulverized, and passed through a 40-mesh sieve. The powdered material was steeped in water:ethanol (20:80; v/v) for 7 days and subsequently filtered through Whatman No. 41 filter paper. The filtrate was reduced to dryness on a rotary evaporator and lyophilized to yield $130.2 \mathrm{~g}$ of dry crude extract, resulting in a drug extract ratio of 7.6:1.

\section{Separation and identification of constituents by ultra-performance liquid chromatography-mass spectrometry}

Chromatographic analyses were performed using a Waters Acquity UPLC H-Class system equipped with a diode array detector (DAD) and a Waters Xevo TQ-S tandem quadrupole mass spectrometer with a Z-spray source operating in the negative ion mode. Stock solutions containing $1.0 \mathrm{mg} / \mathrm{mL}$ of extract or the standards acteoside, isoacteoside, 6'-acetylacteoside, and 4',4"',5,5'"-tetrahydroxy-6,6",3'”trimethoxy-[C7-O-C7'"]-biflavone in LC-grade methanol were prepared separately, with sonication for 30 min each when necessary, and filtered through $0.45 \mu \mathrm{m}$ Millipore filters (Merck Millipore). Solutions were diluted to $10 \mu \mathrm{g} / \mathrm{mL}$ with methanol, and aliquots $(5 \mu \mathrm{L})$ were injected onto a Sigma-Aldrich Ascentis Express $C_{18}$ column $(100 \times 4.6 \mathrm{~mm}$ i.d.; $2.7 \mu \mathrm{m}$ particle size). The mobile phase consisted of water containing $0.1 \%$ formic acid (solvent $A$ ) and methanol containing $0.1 \%$ formic acid (solvent $B$ ) supplied at a flow rate of $0.5 \mathrm{~mL}$ / min according to the elution profile: isocratic with $3 \% \mathrm{~B}$ between 0 and $4 \mathrm{~min}$, followed by linear gradients from 3 to $60 \%$ B between 4 and 19 min and from 60 to $90 \%$ B between 19 and 23 min, and finally returned to $3 \% \mathrm{~B}$ between 23 and $28 \mathrm{~min}$. The effluent was monitored by DAD in the range of 210 to $720 \mathrm{~nm}$ and by MS with the optimized source and operating parameters as follows: capillary volt- age $2.50 \mathrm{kV}$, Z-spray source temperature $150{ }^{\circ} \mathrm{C}$, desolvation temperature $\left(\mathrm{N}_{2}\right) 350^{\circ} \mathrm{C}$, desolvation gas flow $600 \mathrm{~L} / \mathrm{h}$, and mass range of $\mathrm{m} / \mathrm{z} 150$ to 600 in the full scan mode.

\section{Purification of identified constituents}

The crude hydroethanolic extract $(10 \mathrm{~g})$ was dissolved in water:ethanol (50:50; v/v) and partitioned consecutively against hexane, ethyl acetate, and n-butanol. The n-butanol fraction was concentrated on a rotary evaporator and a $3 \mathrm{~g}$ sample of the fractionated extract was applied to a glass column $(10 \times 3 \mathrm{~cm}$ o.d.) filled with C-18 RP silica gel (230-400 mesh; Sigma-Aldrich) and eluted with water, followed by successive mixtures of water:methanol (90:10, $50: 50$, and 10:90; $v / v)$. The subfraction obtained by elution with water:methanol (90:10; v/v) was further purified by RP-HPLC using a Shimadzu LC-20AP System coupled to an SPD-20A UV/Vis detector and equipped with a Phenomenex Luna ${ }^{\circledR} \mathrm{C}-18$ column $(250 \times 10$ $\mathrm{mm}$ i.d.; $5 \mu \mathrm{m}$ particle size). The mobile phase was water:methanol commencing at 90:10 (v/v) and changing to $30: 70(\mathrm{v} / \mathrm{v})$ in $100 \mathrm{~min}$ to yield the four known compounds acteoside $(750 \mathrm{mg})$, isoacteoside (430 mg), 6'-acetylacteoside (42 mg), and 4',4'", 5,5"'-tetrahydroxy-6,6",3"'-trimethoxy-[C7-O-C7']-biflavone (13 mg). The flow rate of the mobile phase was $1 \mathrm{~mL} / \mathrm{min}$, the injection volume was $500 \mu \mathrm{L}$, the chromatogram was recorded at $340 \mathrm{~nm}$, and UV spectra were obtained in the range of 240 to $400 \mathrm{~nm}$. The identities of the purified constituents were confirmed from their ${ }^{1} \mathrm{H}-(500 \mathrm{MHz})$ and ${ }^{13} \mathrm{C}-\mathrm{NMR}(125 \mathrm{MHz})$ spectra recorded on a Bruker model DPX 500 spectrometer, and comparison of the data with those available in the literature $[18,19,41]$. Purities of the isolated compounds were confirmed by UPLC-DAD-MS ( Fig. 1b-d) and NMR ( Fig. S1-S12, Supporting Information).

\section{Quantification of acteoside by an HPLC-diode array detector}

A sample (1 mg) of the dried hydroethanolic extract was redissolved in $1 \mathrm{~mL}$ of a mixture (80:20; v/v) of methanol (J.T. Baker HPLC grade) and Milli-Q Ultrapure water (Merck Millipore), sonicated for $30 \mathrm{~min}$, and filtered through a $0.45-\mu \mathrm{m}$ Millipore filter. Aliquots $(20 \mu \mathrm{L})$ of 
this solution were analyzed on a Shimadzu LC-10APvp system coupled to an SPD-M10Avp DAD and fitted with a Phenomenex Luna C18 column $(250 \times 4.6 \mathrm{~mm}$ i.d., $5 \mu \mathrm{m})$ protected by a Phenomenex C18 precolumn $(4.0 \times 3.0 \mathrm{~mm}$ i.d., $5 \mu \mathrm{m})$. Separations were carried out at room temperature $\left(22 \pm 1^{\circ} \mathrm{C}\right)$ using a mobile phase comprising acetic acid $0.1 \%$ in water (solvent $A$ ) and methanol (solvent $B$; J.T. Baker HPLC grade) supplied at a constant flow rate of $1.0 \mathrm{~mL}$ / min according to the program: linear gradient from 10 to $70 \% \mathrm{~B}$ between 0 and $32 \mathrm{~min}$, from 70 to $10 \% \mathrm{~B}$ between 32 and $35 \mathrm{~min}$, and a final isocratic elution with $10 \% \mathrm{~B}$ between 35 and $40 \mathrm{~min}$. The detection wavelength was set at $330 \mathrm{~nm}$.

The content of acteoside in the extract was estimated using acteoside (Sigma-Aldrich; CAS no. 61276-17-3) as the external standard. Solutions containing 500, 250, 125, 62.5, 31.2, and $15.6 \mu \mathrm{g} /$ $\mathrm{mL}$ of the reference standard were prepared, and calibration curves were constructed by subjecting each solution to HPLC analysis in triplicate [42]. The ratio of peak area of standard acteoside to the corresponding concentration of analyte was established through linear regression of the standard curves ( - Fig. S13, Supporting Information). Analytical data were validated with respect to linearity, precision, and accuracy according to the guidelines issued by the Agência Nacional de Vigilância Sanitária [42]. Limits of detection (LoD) and quantitation (LoQ) of acteoside were 0.30 and $0.92 \mu \mathrm{g} / \mathrm{mL}$, respectively.

\section{Monoamine oxidase-A inhibition assays}

Recombinant human MAO-A, tyramine, clorgyline, vanillic acid, 4-aminoantipyrine, and horseradish peroxidase were purchased from Sigma-Aldrich. MAO-A inhibition assays were performed using 96-well plates following a modified version of the method described by López et al. [43]. Each well was loaded with $50 \mu \mathrm{L}$ of chromogenic solution ( $0.8 \mathrm{mM}$ vanillic acid, $2.5 \mathrm{mM}$ 4-aminoantipyrine, and $4 \mathrm{U} / \mathrm{mL}$ horseradish peroxidase in phosphate buffer at $\mathrm{pH} 7.6$ ), $100 \mu \mathrm{L}$ of $3 \mathrm{mM}$ tyramine, and a $50-\mu \mathrm{L}$ aliquot of the crude hydroethanolic extract or one of the purified phenylethanoids dissolved in methanol. Finally, $50 \mu \mathrm{L}$ aliquots of $8 \mathrm{U} / \mathrm{mL}$ MAO-A were added to each of the wells and the plate was incubated at $37^{\circ} \mathrm{C}$ for $30 \mathrm{~min}$, during which time absorbances were recorded every 5 min using a microplate reader. Clorgyline ( $\geq 97 \%$ GC; Sigma-Aldrich) and methanol were included as positive and negative controls, respectively, on each assay plate.

\section{Statistical analysis}

Three independent assessments of MAO-A inhibitory activities were performed and the acquired data were analyzed using GraphPad Prism software. The $\mathrm{IC}_{50}$ values of the hydroethanolic extract, purified phenylethanoids and the positive control were calculated by nonlinear regression, simulating plots of log (inhibitor concentration) versus normalized percentage inhibition.

\section{Supporting information}

$\mathrm{H}$ - and ${ }^{13} \mathrm{C}$-NMR spectra of acteoside, isoacteoside, 6'-acetylacteoside, and 4',4"',5,5'"-tetrahydroxy-6,6"',3'"'-trimethoxy-[C7-OC7"']-biflavone and HSQC/HMBC correlation analyses for the three phenylethanoids are available as Supporting Information.

\section{Conflict of Interest}

The authors declare no conflict of interest.

\section{References}

[1] World Health Organization. Depression and Other Common Mental Disorders: Global Health Estimates. Geneva: WHO; 2017

[2] Ferguson JM. SSRI antidepressant medications: Adverse effects and tolerability. Prim Care Companion J Clin Psychiatry 2001; 3: 22-27

[3] van der Watt G, Laugharne J, Janca A. Complementary and alternative medicine in the treatment of anxiety and depression. Curr Opin Psychiatry 2008; 21: 37-42

[4] Sarris ], Mclntyre E, Camfield DA. Plant-based medicines for anxiety disorders, part 1: A review of preclinical studies. CNS Drugs 2013; 27 : 207-219

[5] Sarris ], Mclntyre E, Camfield DA. Plant-based medicines for anxiety disorders, part 2: A review of clinical studies with supporting preclinical evidence. CNS Drugs 2013; 27: 301-319

[6] Del Vitto LA, Petenatti EM, Petenatti ME. Recursos herbolarios de San Luis (República Argentina). Primera parte: Plantas Nativas. Multequina 1997; 6: 49-66

[7] González Y, Arrúa RD, Rojas GD, García MG. Etnofarmacobotánica foliar de "burrito", Aloysia polystachya (Griseb.) Moldenke (Verbenaceae), cultivado en Paraguay. Rojasiana 2014; 13: 31-41

[8] Mora S, Díaz-Véliz G, Millán R, Lungenstrass H, Quirós S, Coto-Morales T, Hellión-Ibarrola MC. Anxiolytic and antidepressant-like effects of the hydroalcoholic extract from Aloysia polystachya in rats. Pharmacol Biochem Behav 2005; 82: 373-378

[9] Hellión-Ibarrola MC, Ibarrola DA, Montalbetti Y, Kennedy ML, Heinichen O, Campuzano M, Tortoriello J, Fernández S, Wasowski C, Marder M, De Lima TCM, Mora S. The anxiolytic-like effects of Aloysia polystachya (Griseb.) Moldenke (Verbenaceae) in mice. J Ethnopharmacol 2006; 105: 400-408

[10] Hellión-Ibarrola MC, Ibarrola DA, Montalbetti Y, Kennedy ML, Heinichen O, Campuzano M, Ferro EA, Alvarenga N, Tortoriello J, De Lima TCM, Mora S. The antidepressant-like effects of Aloysia polystachya (Griseb.) Moldenke (Verbenaceae) in mice. Phytomedicine 2008; 15: 478-483

[11] Herraiz T, González D, Ancín-Azpilicueta C, Arán V], Guillén H. $\beta$-Carboline alkaloids in Peganum harmala and inhibition of human monoamine oxidase (MAO). Food Chem Toxicol 2010; 48: 839-845

[12] Herraiz T, Guillén H, Arán V], Salgado A. Identification, occurrence and activity of quinazoline alkaloids in Peganum harmala. Food Chem Toxicol 2017; 103: 261-269

[13] Herraiz T, Guillén H. Monoamine oxidase-A inhibition and associated antioxidant activity in plant extracts with potential antidepressant actions. Bio Med Res Int 2018; 1018: 4810394

[14] Carradori S, D’Ascenzio M, Chimenti P, Secci D, Bolasco A. Selective MAO-B inhibitors: A lesson from natural products. Mol Divers 2014; 18: $219-243$

[15] Fajemiroye JO, Silva DM, Oliveira DR, Costa EA. Treatment of anxiety and depression: Medicinal plants in retrospect. Fundam Clin Pharmacol 2016; 30: 198-215

[16] Fišar Z. Drugs related to monoamine oxidase activity. Prog Neuropsychopharmacol Biol Psychiatry 2016; 69: 112-124

[17] Naoi M, Maruyama W, Shamoto-Nagai M. Type A monoamine oxidase and serotonin are coordinately involved in depressive disorders: From neurotransmitter imbalance to impaired neurogenesis. J Neural Transm 2017; 125: 53-66 
[18] Pettit GR, Numata A, Takemura T, Ode RH, Narula AS, Schmidt JM, Cragg GM, Pase CP. Antineoplastic agents, 107. Isolation of acteoside and isoacteoside from Castilleja linariaefolia. J Nat Prod 1990; 53: 456-458

[19] Munkombwe NM. Acetylated phenolic glycosides from Harpagophytum procumbens. Phytochemistry 2003; 62: 1231-1234

[20] Barbosa FG, Lima MAS, Silveira ER. Total NMR assignments of new [C7-O-C7"]-biflavones from leaves of the limonene-carvone chemotype of Lippia alba (Mill) N. E. Brown. Magn Reson Chem 2005; 43: 334-338

[21] Pina ES, Coppede JS, Sartoratto A, Fachin AL, Bertoni BW, França SC, Pereira AMS. Antimicrobial activity and chemical composition of essential oils from Aloysia polystachya (Griseb.) Moldenke grown in Brazil. J Med Plant Res 2012; 6: 5412-5416

[22] Dias KST, de Paula CT, Riquiel MM, Lago ST, Costa KCM, Vaz SM, Machado RP, Lima LMS, Viegas C Jr.. Aplicações recentes da abordagem de fármacos multialvo para o tratamento da doença de Alzheimer. Rev Virtual Quim 2015; 7: 609-648

[23] Wink M. Evolutionary advantage and molecular modes of action of multi-component mixtures used in phytomedicine. Curr Drug Metab 2008; 9: 996-1009

[24] Wink M. Modes of action of herbal medicines and plant secondary metabolites. Medicines 2015; 2: 251-286

[25] Barbosa MLC. Doenças multifatoriais e os desafios no planejamento de fármacos multialvos: A contribuição do laboratório de avaliação e síntese de substâncias bioativas - lassbio. Rev Virtual Quim 2015; 7: 576-593

[26] Li M, Zhou F, Xu T, Song H, Lu B. Acteoside protects against 6-OHDA induced dopaminergic neuron damage via Nrf2-ARE signaling pathway. Food Chem Toxicol 2018; 119: 6-13

[27] Razavi M, Zargarani N, Hosseinzadeh H. Anti-anxiety and hypnotic effects of ethanolic and aqueous extracts of Lippia citriodora leaves and verbascoside in mice. Avicenna J Phytomed 2017; 7: 353-365

[28] Miller AH, Raison CL. The role of inflammation in depression: from evolutionary imperative to modern treatment target. Nat Rev Immunol 2016; 16: 22-34

[29] Rao YK, Fang SH, Hsieh SC, Yeh TH, Tzeng YM. The constituents of Anisomeles indica and their anti-inflammatory activities. J Ethnopharmacol 2009; 121: 292-296

[30] Lee JH, Lee JY, Kang HS, Jeong CH, Moon H, Whang WK, Kim C], Sim SS. The effect of acteoside on histamine release and arachidonic acid release in RBL-2H3 mast cells. Arch Pharmacal Res 2006; 29: 508-513

[31] Lee JY, Woo ER, Kang KW. Inhibition of lipopolysaccharide-inducible nitric oxide synthase expression by acteoside through blocking of AP-1 activation. J Ethnopharmacol 2005; 97: 561-566
[32] Nam SY, Kim HM, Jeong HJ. Attenuation of IL-32-induced caspase-1 and nuclear factor-kB activations by acteoside. Int Immunopharmacol 2015; 29: 574-582

[33] Wohleb ES, Franklin T, Iwata M, Duman RS. Integrating neuroimmune systems in the neurobiology of depression. Nat Rev Neurosci 2016; 17 : 497-511

[34] Maes M, Leonard BE, Myint AM, Kubera M, Verkerk R. The new '5-HT' hypothesis of depression: cell-mediated immune activation induces indoleamine 2,3-dioxygenase, which leads to lower plasma tryptophan and an increased synthesis of detrimental tryptophan catabolites (TRYCATs), both of which contribute to the onset of depression. Prog Neuropsychopharmacol Biol Psychiatry 2011; 35: 702-721

[35] He J, Hu XP, Zeng Y, Li Y, Wu HQ, Qiu RZ, Ma W], Li T, Li CY, He ZD. Advanced research on acteoside for chemistry and bioactivities. J Asian Nat Prod Res 2011; 13: 449-464

[36] Chen CH, Lin YS, Chien MY, Hou WC, Hu ML. Antioxidant and antihypertensive activities of acteoside and its analogs. Bot Stud 2012; 53: 421-429

[37] Mao S, Wang K, Lei Y, Yao S, Lu B, Huang W. Antioxidant synergistic effects of Osmanthus fragrans flowers with green tea and their major contributed antioxidant compounds. Sci Rep 2017; 7: 46501

[38] Wang H, Xu Y, Yan J, Zhao X, Sun X, Zhang Y, Guo J, Zhu C. Acteoside protects human neuroblastoma SH-SY5Y cells against beta-amyloid induced cell injury. Brain Res 2009; 1283: 139-147

[39] Kurisu M, Miyamae Y, Murakami K, Han J, Isoda H, Irie K, Shigemori H. Inhibition of amyloid $\beta$ aggregation by acteoside, a phenylethanoid glycoside. Biosci Biotechnol Biochem 2013; 77: 1329-1332

[40] Xu Y, Wang C, Klabnik J], O'Donnell JM. Novel therapeutic targets in depression and anxiety: antioxidants as a candidate treatment. Curr Neuropharmacol 2014; 12: 108-119

[41] Santos Galíndez J, Diaz-Lanza AM, Fernández Matellano L, Rumbero Sánchez A. A new phenylpropanoid glycoside isolated from Scrophularia scorodonia L. Magn Reson Chem 2000; 38: 688-691

[42] Agência Nacional de Vigilância Sanitária. Resolução da Diretoria Colegiada (RDC) no 166, de 24 de julho de 2017. Validação de métodos analíticos. Available at https://www20.anvisa.gov.br/coifa/ pdf/rdc166.pdf Accessed August 20, 2018

[43] López V, Les F, lannarelli R, Caprioli G, Maggi F. Methanolic extract from red berry-like fruits of Hypericum androsaemum: Chemical characterization and inhibitory potential of central nervous system enzymes. Ind Crops Prod 2016; 94: 363-367 